\title{
Nilai-nilai Pendidikan dalam Pertunjukan Teater Rakyat Kondobuleng
}

\author{
Asia Ramli \\ Program Studi Seni Drama, Tari dan Musik Jurusan Seni Pertunjukan Fakultas Seni dan Desain \\ Universitas Negeri Makassar \\ asiaramli@unm.ac.id
}

\begin{abstract}
ABSTRAK
Penelitian ini bertujuan untuk mendeskripsikan dan menganalisis nilai-nilai pendidikan dalam pertunjukan teater rakyat Kondobuleng. Metode penelitian menggunakan jenis penelitian kualitatif dengan pendekatan interdisiplin. Pendekatan ini mengkaji dan menganalis objek penelitian secara komprehensif. Teknik analisis data menggunakan teknik observasi, wawancara, dan dokumentasi. Hasil penelitian menunjukkan: Pertama, nilai pendidikan melalui sistem pewarisan, antara lain nilai adat pangngadakkang, nilai tau yang disebut sipakatau. Nilai adat istiadat ini terus ditanamkan secara turun temurun dari satu generasi ke generasi selanjutnya. Kedua, nilai pendidikan melalui pembelajaran di Sanggar, antara lain: nilai siri' na pace, yaitu saling menhgargai dan menghormati, sebagai nilai utama dan menjadi landasan falsafah hidup orang Bugis-Makassar. Nilai ini berkenaan dengan etik, beradab, berakhlak, sopan, jujur, dalam memelihara hubungan sesama manusia. Ketiga, nilai pendidikan melalui pertunjukan yaitu nilai estetis yang mengajarkan kepada kita untuk menghargai keindahan seni, keindahan moral, dan keindahan intelektual. Nilai ini direpresentasikan melalui estetika komunal yang komedial, spontan, inovatif, kreatif, komunikatif, dan menghibur.
\end{abstract}

Kata kunci: nilai, pendidikan, teater

\section{ABSTRACT}

This study aims to describe and analyze the values of education in the Kondobuleng folk theater performance. The research method uses qualitative research with an interdisciplinary approach. This approach examines and analyzes the object of research comprehensively. The data analysis technique used observation, interview, and documentation techniques. The results showed: First, the value of education through the inheritance system, including the traditional pangngadakkang value, the value of tau which is called sipakatau. These customs values continue to be instilled from generation to generation from one generation to the next. Second, the value of education through learning at the Sanggar, among others: the value of siri 'na pace, which is mutual respect and respect, as the main value and the basis of the philosophy of life of the Bugis-Makassar people. This value relates to ethics, being civilized, moral, polite, honest, in maintaining human relationships. Third, the value of education through performance is an aesthetic value that teaches us to appreciate the beauty of art, moral beauty, and intellectual beauty. This value is represented through comedial, spontaneous, innovative, creative, communicative, and entertaining communal aesthetics.

Keywords: values, education, theater

\section{PENDAHULUAN}

Pertunjukan teater rakyat Kondobuleng pada awalnya dikenal oleh masyarakat suku Bajo di Teluk Bone sebagai ritual lalu berubah menjadi permainan. Namun demikian, masyarakat setempat tidak mengenalnya lagi. Pertunjukan ini justeru ditemukan di Pangkajene dan Kepulauan dan dikenal sebagai tarian. Bahkan sangat dikenal sebagai pertunjukan teater rakyat di Kelurahan Paropo Kecamatan Panakung Kota Makassar, karena sering dipentaskan oleh Sanggar Seni I Lolo Gading di berbagai acara dan festival.
Menurut Lolo Deri putera Kepala Suku Bajo di Teluk Bone, permainan Kondobuleng dalam bentuk ritual dan dilakukan pada waktu malam saat warga kampung dalam keadaan sepi. Paparan ini diperkuat oleh putera Raja Bone terakhir Andi Baso Bone Bin A. Baso Mappasissi Petta Awangpone. Di dalam lontara disebutkan bahwa dalam proses ritual Kondobuleng itu dibacakan mantra oleh kepala suku, memohon kepada dewa-dewa agar dapat menurunkan amanah kepada Kondobuleng. Misalnya bagaimana menjaga alam, termasuk bagaimana menangkap ikan secara arif. Walaupun hanya 
diwujudkan sebagai bangau putih, tapi Kondobuleng dianggap sebagai jelmaan manusia suci (Ramli, 2018).

Pertunjukan teater rakyat Kondobuleng yang dimainkan oleh Sanggar Seni Tradisional I Lolo Gading, terdiri atas satu babak dan delapan adegan. Teater bernafaskan komedi satir ini dimainkan oleh lima orang yang memerankan lima tokoh nelayan, satu tokoh memerankan Kondobuleng (bangau putih), satu tokoh memerankan Pemburu, dan satu tokoh memerankan Pak Lurah. Dalam pertunjukannya, pemain menggunakan dialog bahasa daerah dan Indonesia dengan , diiringi oleh kelompok musik sepuluh orang.

Pada tahap awal atau eksposisi pertunjukan, menggambarkan tokoh Kondobuleng muncul di pesisir. Ia secara akrab mencari ikan bersama lima nelayan, yaitu Pabalewang, Pajala, Pabalibodo, Pasodo dan Papaccalak. Pada tahap komplikasi dilukiskan dengan munculnya tokoh Pemburu menembak Kondobuleng. Tapi bukan Kondobuleng saja yang roboh tetapi juga si Pemburu terpental roboh dan bahkan menghilang tiba-tiba. Para nelayan bermusyawarah, memecahkan masalah untuk mencari Pemburu dan Kondobuleng. Mereka pun mencarinya dengan menggunakan tubunhnya sebagai sampan. Tiba-tiba gelombang datang, sampan terbalik. Mereka pun berenang ke pantai seberang dengan beragam gaya. Mereka tiba dan ditemukan Pemburu terbaring pingsan di pantai. Pajala membacakan mantra untuk menghidupkan Pemburu. Setelah Pemburu sadar, mereka bersama-sama mencari Kondobuleng dengan menyusuri pantai. Mereka pun menemukan Kondobuleng yang sedang terkapar di pantai. Pada tahap penyelesaian, mereka menyanyikan lagu Mala-mala Hatté dengan iringan musik sakral menghidupkan Kondobuleng. Perlahan tampak Kondobuleng bergerak lalu pelanpelan berdiri, berputar, mengepakkan sayap, terbang mengelilingi arena dan melayang pergi. Semua memperhatikan tingkah Kondobuleng.

Claire Holt menulis tentang kesenian ini dalam bukunya Dances Ques in Celebes, terbit tahun 1939 di Paris. B.F. Mathes telah mengumpulkan pula berbagai syair lagu dari, antara lain I Lologading, Daeng Camummu. Melihat data ini, maka dapat diperkirakan bahwa teater rakyat ini telah dikenal dalam masyarakat Makassar khususnya di daerah Paropo, Barombong, Cikoang, Lakiung Topabiring sejak abad ke-15 (Lathief, 2017).
Masalah kemudian muncul, dalam perjalanannya yang sangat lamban, permainan Kondobuleng yang awalnya dari ritual menjelma permainan oleh suku Bajo ini, telah banyak mengalami alieanasi, karena produk budaya warisan masa lampau ini tidak bertahan dan berkembang, bahkan tidak lagi dikenal oleh masyarakat pesisir di pantai Teluk Bone, tempat asal ditemukannya. Namun demikian, permainan ini masih dapat ditemukan di Pangkajene dan Kepulauan dan dikenal sebagai tarian. Sedang di Kelurahan Paropo Kecamatan Panakukang, dikenal sebagai pertunjukan teater rakyat Kondobuleng.

Melalui Sanggar Seni Tradisional I Lolo Gading di Kelurahan Paropo pimpinan M. Arsyad K (Daeng Aca), pertunjukan teater rakyat Kondobuleng terus dilestarikan, diwariskan dan dikembangkangkan, karena dianggap teater ini menjadi warisan budaya yang mengandung nilai-nilai pendidikan. Pewarisan nilai-nilai pendidikan dalam teater ini terus ditradisikan secara turun temurun, walaupun sering kali sulit dirunut pangkal mulanya. Nilai-nilai pendidikan yang ditradisikan itu, kiranya telah menjadi pula semacam kebutuhan atau kelengkapan dari masyarakat yang bersangkutan.

Nilai-nilai pendidikan terkait dengan aspek penting dalam sistem pewarisan kebudayaan, yaitu dipandang sebagai suatu warisan yang terus dipelajari, dihayati dan dimiliki bersama para warga masyarakat pendukungnya. Proses pewarisan kebudayaan sebagai keseluruhan yang kompleks mencakup pengetahuan, teknologi, kepercayaan, seni, moral, hukum, tradisi atau adat istiadat beserta nilai-nilainya, senantiasa terjadi melalui proses pendidikan (Kuper: 2000: 200; lihat Kuntjaraningkarat, 1990: 2; lihat Rohidi, 2000: 28). Dengan demikian, pendidikan dipandang sebagai satu sarana dalam upaya pelestarian untuk mempertahankan nilai-nilai kebenaran, kebajikan dan dihargai. Pendidikan menerapkan pembentukan nilai kepada anak, menghasilkan sikap yang mencerminkan nilainilai kebajikan, membimbing perilaku yang konsisten dengan nilai-nilai tersebut. Pendidikan membantu dan membimbing perilaku anak-anak agar memahami, menyadari, dan mengalami nilai-nilai serta mampu menempatkannya secara integral dalam kehidupan.

Sebagai hasil kebudayaan, pertunjukan teater rakyat Kondobuleng mengandung nilai pendidikan. Pendidikan dengan kebudayaan 
saling berkesinambungan dan tidak dapat dipisahkan karena saling membutuhkan antara satu sama lainnya. Cara yang paling efektif dalam mentransmisikan nilai budaya adalah dengan cara mentransmisikan melalui proses pendidikan. Salah satu cara yang paling efektif dalam mentransmisikan nilai pendidikan adalah melalui seni pertunjukan teater. Sebab dalam seni pertunjukan teater mengandung seni kolektif yang diekspresikan melalui simbol-simbol bahasa, dialog, tokoh/karakter, rupa/dekor/properti, tari atau gerak, kostum, rias, music dan lagu.

Dengan demikian, maka diperlukan penelitian yang matang yang berfokus pada nilai pendidikan melalu sistem pewarisan, melalui pembelajaran di sanggar, dan melalui pertunjukan teater rakyat Kondobuleng yang dipentaskan oleh Sanggar Seni Tradisional I Lolo Gading. Penelitian ini menjadi dirasa sangat signifikan dan penting sebagai dasar pijkan untuk keberlangsungan dan konservasi pertunjukan teater ini agar tidak meninggalkan nilai-nilai pendidikan di tengah gencarnya industrialisasi dan moderniasasi.

\section{METODE PENELITIAN}

Penelitian ini mendeskripsikan dan menganalisis fokus masalah nilai pendidikan melalu sistem pewarisan, melalui pembelajaran di sanggar, dan melalui pertunjukan teater rakyat Kondobuleng. Penelitian ini merupakan jenis penelitian kualitatif dengan pendekatan interdisiplin. Pendekatan ini mengkaji dan menganalis objek penelitian secara komprehensif. Menurut Rohidi (2011: 65), kajian interdisiplin menggunakan teori-teori yang relavan untuk pemecahan secara komprehensif terhadap masalah-masalah yang menjadi sasaran kajian. Apabila kajian interdisiplin tidak sesuai dengan kegunaan yang diharapkan, maka kajian tersebut tidak akan dimanfaatkan.

Dalam mengumpulkan data yang valid, penelitian ini menggunakan teknik observasi, wawancara, dan dokumentasi. Data yang dikumpulkan besumber dari data primer dan data sekunder. Dalam menganalisis data, penelitian ini mengacu pada analisis data Miles dan Huberman (1994) yang menggambarkan tiga alir utama dalam analisis, yaitu: reduksi data, penyajian data, dan penarikan kesimpulan dari dua yang pertama. Ketiga komponen analisis tersebut aktifitasnya dilakukan dalam bentuk interaktif dengan proses pengumpulan data sebagai suatu proses siklus (dalam Rohidi, 2011: 233 - 240).

\section{HASIL \& PEMBAHASAN}

1. Nilai Pendidikan melalui Sistem

\section{Pewarisan}

Berdasarkan hasil wawancara dengan Bapak M. Arsad K yang lebih akrab disapa Daeng Aca, pertunjukan teater rakyat Kondobuleng merupakan warisan dari leluhurnya. Pada masa itu, Belanda dan Raja Gowa memberikan izin kepada neneknya untuk mementaskan Kondobuleng di berbagai tempat, termasuk di istana Gowa. Dia diberikan amanah langsung oleh pamannya yang telah dianggap sebagai bapaknya sendiri yaitu Daeng Abbasa untuk meneruskan sanggar seni tradisional, karena ayahnya sudah tua. Waktu itu Daeng Aca baru kelas 4 SD. Dia masih ingat pesan bapaknya:

Begini, Nak, bapak ini sudah
tua, tidak bisa melihat lagi.
Kamu sudah mulai besar, dan
mulai pintar menyanyi dan
memainkan biola. Tapi kamu
harus terus belajar agar lebih
mahir lagi menyanyi dan
memainkan biola. Hanya kamu
yang bisa meneruskan kesenian
tradisional kita. Karena kamu
sekolah, bisa membaca dan
menulis. Karena kamu
merupakan satu-satunya
penerus sanggar.

Daeng Abbasa merupakan pimpinan sanggar seni yang bergelut di dunia kesenian tradisional bersama rumpun keluarganya, antara lain Daeng Madong, Daeng Gudang, Daeng Hadong dan Daeng Parindra. Mereka semua adalah pemain-pemain Kondobuleng.

Dulu, waktu ayah saya
memimpin rombongan
kesenian Kondobuleng dan
melakukan pentas di beberapa
tempat, saya sering diajak ikut
dalam pementasan meskipun
biasanya hanya tidur di paha
bapak saya.Nanti pada saat
adegannya lucu, baru saya
terbangun.

Daeng Aca diajarkan bermain biola oleh ayahnya pada setiap ayahnya pulang dari menjual ikan, karena ayahnya selain pemain biola di Kondobuleng, juga seorang penjual ikan. Dengan tangannya yang masih penuh 
sisik ikan, Daeng Aca diajarkan cara memainkan biola. Tapi sebenarnya, sebelum Daeng Aca diajarkan cara memainkan biola, terlebih dahulu dia diajarkan menyanyi.

Waktu Daeng Aca kelas 4 SD, dia sekolah 2 kali dalam sehari. Pagi hari di sekolah di Panaikang, dan sore hari di sekolah Muallimin yang ada di Paropo. Di masa itu, selain menghabiskan waktunya untuk sekolah pada pagi dan sore hari, dia pun belajar menyanyi dan memainkan biola yang diajarkan oleh ayahnya pada waktu yang kosong.

\section{Kalau pulang sekolah diajarma sama ayah saya. Saya dipangku sambil diajari main biola. Jadi pas pintarma, ayah saya berpesan ke orang-orang "ikau ngaseng anne, iya anne sebagai kuwakili Aca (kalian semua ini Aca sekarang yang mewakili saya). Banyak orang tua waktu itu, tapi saya yang paling tinggi peranku, karena dulu, pabiola itu tidak boleh duduk di atas tidak boleh di bawah. Saya yang pimpin mereka semua karena pintarma menyanyi dan main biola. Saya juga mulai besar waktu itu. Jadi kemana-mana pergi pentas, saya yang pimpin dan memainkan biola. Apalagi waktu itu, hanya saya ji yang pintar menulis sedang yang lain tidak ada sekolahnya. jadi diangkatlah saya jadi ketua sampai sekarang .}

Setelah Daeng Aca mahir menyanyi dan memainkan biola, ayahnya bersama Daeng Pawa bernasar dan menyampaikan kepada teman-temannya kalau Daeng Aca sudah pintar memainkan biola. Maka upacara nasar itu pun dilaksanakan di tengah orang banyak. Ayahnya menyajikan songkolo', telur dan kue-kue tradisional yang dikelilingi janur kuning, serta sajian biola dari Daeng Aca dan musik tradisional dari komunitas sanggar. Masyarakat dan keluarga serumpun banyak yang hadir mengikuti ritual nasar tersebut dan turut menikmati suguhan tradisional.

Beberapa pemain Kondobuleng di Paropo di masa itu, antara lain Daeng Mone, Pak Ismail dan Daeng Dade (ketiganya sudah almarhum). Meskipun Daemg Aca masih kecil waktu itu, namun dia dipercayakan untuk memimpin Sanggar Tradisional I Lolo Gading karena pada saat itu hanya dia yang mahir berbahasa Indonesia dan menempuh pendidikan, sedangkan yang lain tidak. Makanya Daeng Aca dari kecil sudah memimpin pertunjukan Kondobuleng di Paropo.

Ingatan Daeng Aca mulai samar-samar ketika mengingat dan menyebut nama-nama pemain Kondobuleng di masa ia berumur 10 tahun, antara lain Daeng Pawa, Daeng Sudding, Daeng Alli, Daeng Tinri, Daeng Mone, Samailla (alm), Daeng Emba, Daeng Dade' (alm), Daeng Naba, Daeng Moneng (alm), Mustari, Ambo Tibu', Alm. Daeng Gassing, Majid, H. Mado' dan Daeng Rapi'.

Semua yang saya sampaikan ini adalah "kebenaran", bukan de'de-de'de (tidak benar). "tojengngaji kulle dipau" (hanya kebenaranlah yang bisa diucapkan) karena ketika kita menyampaikan sesuatu yang tidak benar sama halnya kita melakukan perbuatan sia-sia.

Tokoh yang paling mendukung Daeng Aca dalam melestarikan, mewariskan dan mengembangkan teater Kondobuleng, pertama adalah almarhum ayahnya, kedua adalah almarhumah istrinya, ketiga adalah puteraputerinya. Selain itu, Daeng Aca juga sangat didukung oleh anggotanya, masyarakat Paropo, kelompok kesenian lain, dan pemerintah daerah. Pemerintah daerahlah yang pertama memperkenalkan teater Kondobuleng di tingkat nasional dan internasional.

Sekitar tahun 1950-an, Daeng Abbasa sudah mementaskan Kondobuleng. Daeng Aca sering ikut bahkan kadang tertidur di paha ayahnya. Dulu, nama kelompok kesenian yang dipimpin ayahnya bernama Kelompok Kesenian Parebana. Alat musik yang dimainkan hampir semua rebana. Tapi ada juga biola dan berbagai alat musik tradisional lain. Pertunjukannya berupa musik dan lagu-lagu tradisional. Semua pemainnya masih serumpun keluarga, diantaranya Daeng Madong. Daeng Parindra, Daeng Hadong, Daeng Gudang, Daeng Baga, Daeng Mone, Daeng Dade, Daeng Sudding, Daeng Pawa. Hampir semua pemain ini sudah meninggal. Mereka pentas di kampung-kampung dengan berjalan kaki termasuk pentas di istana raja Gowa di Balla'Lompoa. Melelui mereka, Kondobuleng diwariskan ke rumpun keluarga pada generasi ketiga, antara lain Daeng Naba, Mustari, 
Jumakkara, Rais, Anjar, Usman, Botak, Baharu, Bapong, Idirman, Kahar, Sukri, Abdul Rahman, Jamal, Saparuiddin, Nur, Soga, Sarif, Zul, Anto, Iwan, Subang, Sanusi, Rifki Ramadhan dan Raihan.

Sejak masih kanak-kanak, nilai tradisi, petuah dan amanah orang tua telah ditanamkan dalam diri Daeng Aca. Ia mendapat amanah langsung oleh bapaknya sendiri untuk meneruskan nilai pangngadakkang, yaitu nilainilai tradisi dan adat istiadat yang tertuang dalam kesenian tradisional. Warisan nilai tradisi dan adat istiadat yang didapatkan dari bapaknya itu diejawantahkan oleh Daeng Aca ke dalam tata kerja organisasi di Sanggar Seni Tradisional I Lolo Gading. Di sana ditanamkan adat istiadat, kesopanan, kesantunan, berperilaku baik, kesetiaan dan kejujuran.

Nilai-nilai tersebut dimanifestasikan sebagai "pandangan hidup" Daeng Aca baik di dalam sanggar maupun dalam kehidupan bermasyarakat, baik di kelurahan Paropo maupun di tempat lain. Daeng Aca bersama anggota Sanggar Seni Tradisional I Lolo Gading telah menerima adat secara total dalam kehidupan sistem sosial budaya mereka, telah melahirkan keyakinan dan kepercayaan yang teguh bahwa hanya dengan berpedoman pada adatlah ketenteraman dan kebahagiaan bagi setiap anggota masyarakat dapat terjamin. Unsur kepercayaan dan keyakinan yang telah dimanifestasikan oleh mereka dalam konteks mendukung dan memelihara adat dalam sistem sosial itu, merupakan faktor penunjang utama mengapa pertunjukan teater rakyat Kondobuleng dapat bertahan sampai saat ini.

Dengan demikian, temuan nilai pendidikan melalui sistem pewarisan pertunjukan teater rakyat Kondobuleng dapat disimpulkan, yaitu melalui penanaman nilai pangngadakkang, nilai tau yang disebut sipakatau, nasehat dari para leluhur dan orang tua masih tetap dilestarikan dengan cara menjaga nasehat tersebut melalui ingatan kolektif anggota anggota Sanggar I Lolo Gading pada khususnya dan pada masyarakat Bugis-Makassar pada umumnya. Sistem pewarisan tradisi dan adat istiadat tersebut terus ditanamkan secara turun temurun dari satu generasi ke generasi selanjutnya.

\section{Nilai Pendidikan melalui Pembelajaran di Sanggar}

Sanggar Seni Tradisional I Lolo Gading merupakan salah satu elemen pendudukung terwujudnya pendidikan berbasis seni tradisional dalam masyarakat. Salah satu bentuk peran serta sanggar kesenian ini adalah melakukan pemberdayaan masyarakat dengan memperluas partisipasi masyarakat dalam pendidikan dan pelatihan seni yang meliputi peran serta perorangan, kelompok, keluarga, dan organisasi kemasyarakatan dalam penyelenggaraan dan pelayanan pendidikan dan pelatihan seni. Sanggar ini berperanan sebagai sumber dan pelaksana pendidikan dan pelatihan seni.

Daeng Aca mendirikan Sanggar Seni Tradisional I Lolo Gading Paropo pada tanggal 16 Juni 1978. Sanggar ini bersekretariat rumahnya di Jalan Babussalam IV No 12 Kelurahan Paropo Kecamatan Panakkukang Kota Makassar. Pada awalnya sanggar ini hanyalah suatu kelompok kesenian yang berkecimpung di bidang seni music tradisional. Seiring perjalanan waktu dan perkembangan zaman, kini menjadi sebuah sanggar dengan membina dan mengembangkan berbagai macam bidang seni khususnya seni tari, musik dan teater.

Sanggar Seni Tradisional I Lolo Gading mulai berkembang dan dikenal sejak Daeng Aca bekerja di Taman Budaya pada tahun 80-an. Nama-nama anggotanya di generasi ketiga yang aktif dalam memainkan teater Kondobuleng yaitu Kahar sebagai Kondo, Sukri sebagai Pemburu/Tuan, Mustari sebagai Pajala, Abdul Rahman sebagai Pabalewang, Jamal sebagai Pabalibodo, Saparuddin sebagai Pasodo. Adapun pemusik, antara lain Nur, Soga, Sarif, Zul, Anto, Iwan, Subang, Sanusi, Rifki Ramadhan, dan Raihan.

Awalnya Daeng Aca mengajarkan teater Kondobuleng ke generasi ketiga ini dengan terlebih dahulu mengajarkan Gandrang Bulo Anak-anak. Kemudian setelah itu ia mengajarkan tempo, lalu menyanyi dan bermain musik. Ia dibantu oleh Burhanuddin dalam mengajarkan peran, gerak lucu dan adegan. Selebihnya para pemain dibebaskan untuk mengembangkan setiap peran yang diberikan. Bersama Burhanuddin, ia mengajarkan beberapa adegan yang dianggap sulit, diantaranya yaitu adegan perahu dengan menggunakan tubuh para pemain sebagai perahu.

Beberapa materi dalam proses pembelajaran seni di Sanggar Seni Tradisional I Lolo Gading, meliputi: pelatihan music (tabuhan gendang, kecapi, suling, pui-pui: pelatihan bidang tari (paduppa, pakkarena, pattennung, pakkurusumanga, gandrang bulo, bosara, pagellu); pelatihan teater (olah tubuh, 
vokal, rasa, pemeranan); pelatihan rias pengantin; dan pelatihan kostum/busana tradisional.

Berbagai event telah dilakoninya baik di tingkat kabupaten, provinsi, tingkat nasional maupun internasional dalam rangka memperkenalkan budaya Sulawesi Selatan. Event yang dipernah diikuti, antara lain: Pertunjukan Seni dan Budaya Sulawesi Selatan di Singapura, Brunei Darussalam, Jepang Korea Selatan dan Amerika Serikat dalam rangka pameran Usaha Dagang Sedunia pada tahun 1992; Festival Istiqlal Jakarta, mewakili Sulawesi Selatan pada tahun 1993; Pertunjukan Seni Tradisional Sulawesi Selatan di Malaysia dalam rangka menyambut tahun baru 2002; Peresmian Bugis - Johor di Kualalumpur pada tahun 2003; Festival Seni dan Musik Tradisional Lagaligo di Kabupaten Barru pada tahun 2003; Festival Sawerigading di Masamba pada tahun 2003; Penyambutan tamu negara atau kepala daerah lain; Forum Sastra Kepuluan dan Kampung Budaya; Festival Kampung Budaya sejak 2014 sampai tahun 2017 di Makassar; Pekan Teater Nasional di Samarinda tahun 2019. Beberapa kota-kota besar di Indonesia yang pernah di tempati Pertunjukan Kondobuleng yaitu Pulau Jawa, Sumatera, bahkan pernah pentas di luar negeri diantaranya Korea Selatan, Jepang, Singapura, Malaysia (sudah 5 kali) dan Amerika Serikat. Pentas Kondobuleng di Amerika Serikat didampingi oleh Kepala Suaka.

Daeng Aca bersyukur karena dapat mengajarkan dan mementaskan teater rakyat Kondobuleng dan dinikmati oleh masyarakat luas, bahkan masyarakat mancanegara. Dia merasa bahagia telah mengajarkan teater Kondobuleng kepada anggotanya walaupun ada beberapa muridnya yang setelah mendapatkan ilmu, lalu kemudia mereka membuat grup kesenian baru. Tapi ia senang, karena berkat ajarannyalah akhirnya mereka dapat membuat grup baru. Dan berkat mereka jugalah kesenian ini masih bertahan sampai sekarang.

Kepada anggotanya, Daeng Aca berpesan untuk selalu menjaga nama baik sanggar. Ia berharap agar selalu bersama-sama mengembangkan organisasi, melestarikan dan mengembangkan teater Kondobuleng agar tidak tenggelam ditelan zaman. Mereka memegang motto "hidup saling menghargai dan menghormati". Motto ini mengandung nilai budaya, tradisi, religi, kejujuran, kerendahan hati, kesederhanaan, kerjasama, kemandirian, kebebasan, toleransi, rasa cinta, damai dan kesatuan serta penuh tanggung jawab. Masyarakat di sekitarnya sangat mendukung kehadiran sanggar yang dipimpinnya.

Sanggar Kesenian Tradisional I Lolo Gading mengutamakan kemandirian dalam berproses dan manajemen pentas. Mereka memiliki berbagai fasilitas kelengkapan pentas kesenian tradisional, memeliputi seperangkat peralatan musik, kostum, alat rias, properti, dan sound system. Demi kelancaran dan kulaitas pementasan, mereka selalu membawa sendiri peralatan pentas, terutama jika diundang di berbagai acara atau hajatan di kampung-kampung yang tidak memiliki fasilitas peralatan pertunjukan. Selain pertunjukan teater rakyat Kondobuleng, berbagai macam produksi unggulan Sanggar Seni Tradisional I Lolo Gading Paropo yang dikemas dalam bentuk pertunjukan yang siap dipasarkan, baik tradisional maupan yang telah dikembangkan, antara lain: orkes toriolo, tari Gandrang Bulo, tari Si'ru', dan tari Pepe'pepe'ka rimakka, gendang pengantin, produksi iklan dan film dokumeter.

Konsep pertunjukan yang diajarkan dan ditampilkan oleh Sanggar Seni Tradisional I Lolo Gading konsisten pada pijakan tradisional. Keunikan terletak pada sajian dan reportoar-reportoar tradisional yang sarat dengan pesan moral dan nilai-nilai pendidikan. Pesan tersebut direpresentasikan melalui kemasan humor dengan iringan musik yang dinamis.

Dengan demikian, temuan nilai pendidikan melalui pembelajaran di Sanggar Seni Tradisional I Lolo Gading dapat disimpulkan, yaitu nilai siri' na pace yang mengajarkan kepada kita untuk saling menhgargai dan menghormati sebagai nilai utama dan menjadi landasan falsafah hidup orang Bugis-Makassar. Nilai ini merupakan nilai etik berkenaan dengan akhlak yang baik, adat, sopan santun, jujur, rasa cinta, kesatuan, tanggung jawab, beradab, keluhuran budi dalam memelihara hubungan sesama manusia.

\section{Nilai Pendidikan melalui Pertunjukan}

Berdasarkan hasil data dan kajian teks pertunjukan teater rakyat Kondobuleng yang direpresentasikan oleh Sanggar Seni Tradisional I Lolo Gading sarat dengan nilainilai pendidikan yang dapat kita pelajari, antara lain tema dan isi yang disampaikan menyiratkan nilai etis (moral) dan nilai kemanusiaan serta nilai estetik. Nilai-nilai ini 
mengajarkan kepada kita untuk menghargai keindahan moral, keindahan intelektual, keindahan seni yang menyangkut pengalaman esetetis dari seseorang dalam hubungannya dengan segala sesuatu yang dicerapnya. Baik yang dapat ditangkap oleh indera penglihatan maupun dicerap oleh indera pendengaran.

Nilai-nilai tersebut diturunkan melalui simbol-simbol adegan, ekspresi tokoh/karakter, dialog, dialeg, nyanyian, tari/gerak, kostum dan property dalam pertunjukan teater rakyat Kondobuleng. Nilai tau yang disebut sipakatau, yaitu sikap budaya yang merupakan inti atau pangkalan sikap keterbukaan direpresentasikan oleh kelompok musik pada awal pertunjukan dengan memainkan musik dan lagu Parappasa Empo sebagai penghargaan tamu atau undangan yang hadir. Sikap ini juga direpresentasikan oleh tokoh, peran, dan karakter komunitas Nelayan sebagai simbol yang mewakili sosiokulktural pada masyarakat pesisir Bugis-Makassar. Dengan bertolak dari budaya sipakatau inilah, secara tersirat diwujudkan dalam interaksi sosial di atas panggung bahkan menembus ke ruang penonton dengan mendatangi Pak Lurah yang berada di ruang penonton untuk melaporkan kejadian yang menimpa tokoh Pemburu (Tuan) yang tiba-tiba menghilang saat menembak Kondobuleng sampai roboh ke pantai.

Dialog dalam pertunjukan teater rakyat Kondobuleng mengajarkan kita betapa pentingnya bahasa daerah dengan beragam istilah di dalamnya, yang ternyata di dalamnya terdapat keragaman bahasa dan istilah dari berbagai suku atau etnik, bukan saja suku atau etnik dari Sulawesi Selatan, tapi bahkan Jawa, Arab dan bahasa Inggeris. Dalam hal ini, melalui dialog dan bahkan dialeg para pemain, secara tidak langsung mengajarkan kepada kita nilai-nilai pendidikan multikultural yang saling menghargai dan menghormati keragaman budaya masing-masing.

Dengan demikian, nilai-nilai pendidikan yang terdapat dalam pertunjukan teater rakyat Kondobuleng, baik dalam bentuk adegan, ekspresi tokoh/karakter, dialog, nyanyian, tari/gerak, kostum dan property dapat disimpulkan, yaitu nilai estetis yang mengajarkan kepada kita untuk menghargai keindahan seni, keindahan moral, dan keindahan intelektual. Nilai ini menyangkut pengalaman esetetis dari seseorang dalam hubungannya dengan segala sesuatu yang dicerapnya. Baik yang dapat ditangkap oleh indera penglihatan maupun dicerap oleh indera pendengaran. Nilai ini direpresenatikan melalui estetika komunal yang komedial, menghibur, demokratis, spontan, inovatif, kreatif, dan komunikatif. Kita diajarkan untuk selalu hidup bersama dalam persaudaraan yang sederhana, rukun, damai, saling berinteraksi, bermusyawarah untuk mufakat, tolong menolong, bergotong royong, dan memiliki tanggung jawab dan rasa kesetiakawanan pada setiap masalah yang dihadapi. Kita diajarkan tentang bagaimana mempertahankan dan melanjutkan kehidupan dengan cara selalu berusaha keras (reso) untuk mencapai tujuan yang dicita-citakan bersama. Melalui pertunjukan ini, nilai-nilai tersebut terus direpresentasikan di berbagai acara, baik pada acara pesta perkawinan, acara kitanan, hari ulang tahun kota dan berbagai festival seni dan budaya.

\section{KESIMPULAN \& SARAN}

\section{Kesimpulan}

Pertunjukan teater rakyat Kondobuleng yang dipentaskan oleh Sanggar Seni Tradisional I Lolo Gading Kelurahan Paropo Kecamatan Panakukang Kota Makassar mengandung nilai-nilai pendidikan. Pertama, nilai pendidikan melalui sistem pewarisan, antara lain nilai pangngadakkang, nilai tau yang disebut sipakatau, nasehat dari para leluhur dan orang tua. Sistem pewarisan tradisi dan adat istiadat ini terus ditanamkan secara turun temurun dari satu generasi ke generasi selanjutnya. Kedua, nilai pendidikan melalui pembelajaran di Sanggar, antara lain: nilai siri' na pace yang mengajarkan kepada kita untuk saling menhgargai dan menghormati sebagai nilai utama dan menjadi landasan falsafah hidup orang Bugis-Makassar. Nilai ini merupakan nilai etik berkenaan dengan akhlak yang baik, adat, sopan santun, jujur, rasa cinta, kesatuan, tanggung jawab, beradab, keluhuran budi dalam memelihara hubungan sesama manusia. Ketiga, nilai pendidikan melalui pertunjukan yaitu nilai estetis yang mengajarkan kepada kita untuk menghargai keindahan seni, keindahan moral, dan keindahan intelektual. Nilai ini direpresenatikan melalui estetika komunal yang komedial, menghibur, demokratis, spontan, inovatif, kreatif, dan komunikatif. Kita diajarkan untuk selalu hidup bersama dalam persaudaraan yang sederhana, rukun, damai, saling berinteraksi, bermusyawarah untuk mufakat, tolong menolong, bergotong royong, dan memiliki tanggung jawab dan rasa kesetiakawanan pada setiap masalah yang dihadapi. 


\section{Saran}

Pertama, kepada Sanggar Seni Tradisional I Lolo Gading Kelurahan Paropo Kecamatan Panakukan agar terus mewariskan dan mengembangkan nilai-nilai pendidikan dalam pertunjukan teater rakyat Kondobuleng agar tidak ditelan zaman. Kedua, kepada masyarakat dan pemerintah Kota Makassar serta Provinsi Sulawesi Selatan agar terus mengembangkan nilai-nilai pendidikan dalam pertunjukan teater rakyat Kondobuleng melalui setiap kegiatan, baik kegiatan pemerintah maupun kegiatan non pemerintah. Ketiga, secara khusus disarankan kepada pemerintah Kota Makassar dan Provinsi Sulawesi agar pertunjukan ini dapat dimasukkan dalam kurikulum pendidikan.

\section{DAFTAR PUSTAKA}

Frankena, William, K. 1972. The Encyclopedia of Philosophy, Volume Seven, Editor in Chief: Paul Edwards, Macmillan Publishing Co., Inc. \& The Free Press, New York.

Holt, Claire. 1939. Dence Quest in Celebes. Les Arcives Internationales de la Dance. Paris.

Kuper, Adam \& Kuper Jessica. 2000. Ensiklopedia Ilmu-Ilmu Sosial. Edisi Kedua. Accelerator Lyotard. Jakarta: Raja Grafindo.
Koentjaraningrat . 1990. Pengantar Ilmu Antropologi. PT. Rineka Cipta. Jakarta.

Lathief, Halilintar. 2017. Pagelaran Teater Rakyat - Neo Ganrang Bulo Moneng Sudah Mati. Kementerian Pendidikan dan Kebudayaan - Direktoran Jenderal Kebudayaan - Direktorat Kesenian.

Kattsoff, Louis O. 2004. Pengantar Filsafat, diterjemahkan dari judul Elements of Philosophy oleh Soejono Soemargono. Yogyakarta: Tiara Wacana.

Miles Matthew B. \& A. Michael Huberman. 1992. Analisis Data Kualitatif: Buku Sumber tentang Metode Baru, terj. Tjetjep Rohendi Rohidi. Jakarta: UI Perss.

Ramli, Asia. 2018. Pertunjukan Teater Rakyat Kondobuleng: Bentuk Representasi Identitas, Nilai dan Fungsi Sosiokultural Masyarakat Pesisir Bugis-Makassar. Disertasi. Pascasarjana Univesritas Negeri Semarang.

Rohidi. Rohendi Tjetjep. 2000. Ekspresi Seni Orang Miskin - Adaptasi Simbolik Terhadap Kemiskinan. Bandung: Yayasan Nuansa Cendekia. 2011. Metode Penelitian Seni. Semarang: Cipta Prima Nusantara. 